\title{
La Monarquía española en el actual ceremonial de apertura de la legislatura parlamentaria $(1979-2020)^{1}$
}

\section{The Spanish Monarchy in the current State Opening of Parliament ceremony (1979-2020)}

\author{
Oriol LuJÁN \\ Universidad Complutense de Madrid \\ olujan@ucm.es \\ http://orcid.org/0000-0002-3941-3502
}

Fecha de recepción: 17-11-2019

Fecha de aceptación: 26-03-2020

\begin{abstract}
RESUMEN
Este texto pretende reflexionar sobre la presencia de la Monarquía en las aperturas de las legislaturas parlamentarias de las últimas décadas en la España democrática (1979-2020), a fin de demostrar que, lejos de ser una novedad reciente, parte sustancial de la escenificación del actual rito tiene su origen en el franquismo. Además, el artículo aspira a evidenciar la incidencia que tienen los medios de comunicación en el desarrollo de una ceremonia condicionada por su exposición pública y que se ha ido transformando hasta convertirse, a día de hoy, en un acto cuya puesta en escena no solo magnifican los monárquicos —empezando por el propio rey- sino incluso los propios detractores de la institución. Ello también ayuda a propiciar una dimensión más politizada de la Corona, colocándola en el centro del debate político como la institución central del sistema constitucional español.
\end{abstract}

Palabras clave: Monarquía, apertura de la legislatura parlamentaria

Topónimos: España

Período: Siglos XX-XXI

1 Me gustaría agradecer a Javier Moreno Luzón su amabilidad y predisposición, así como los provechosos consejos recibidos después de leer una primera versión de este texto. También quisiera dar las gracias a John Rogister, Joseba Agirreazkuenaga, Joaquim Verde y a todos los que amablemente ofrecieron enriquecedoras observaciones a una versión anterior del texto, que fue presentada en el 71 congreso de la ICHRPI en Andorra con el título "The Current Spanish State Opening of Parliament's ceremony (1979-2016)". Este trabajo forma parte de una investigación postdoctoral vinculada a una ayuda Juan de la Cierva - Formación del Ministerio de Ciencia, Innovación y Universidades y al proyecto "La nación en escena: símbolos, conmemoraciones y exposiciones, entre España y América Latina (1890-2010)", HAR2016- 75002-P, dirigido por Marcela García Sebastiani y Javier Moreno Luzón 


\section{ABSTRACT}

This text considers the Spanish Monarchy's place within the current democratic system via analysis of the State Opening of Parliament ceremony in recent decades (1979-2020). The aim is to demonstrate that part of the staging of the present-day ceremony has its origins in Francoism and is anything but a novelty. The text also seeks to reveal the mass media's impact upon the act. Subjected to public exhibition, the ceremony has been transformed into an act in which both monarchists starting with the king himself - and critics of the institution have seen their profile raised. Moreover, the organisation of the ritual has also propitiated a more politicised dimension of the Crown, placing it at the centre of the political debate as the central institution of the Spanish constitutional system.

Keywords: Monarchy, State Opening of Parliament

Place names: Spain

Period: $19^{\text {th }}-21$ st centuries

\section{INTRODUCCIÓN}

La Monarquía es una forma de Estado que en muchos lugares del mundo ha sabido sobreponerse a los cambios históricos y adaptarse a las nuevas circunstancias. Fue capaz de sobrevivir al fin del Antiguo Régimen, aceptando la posición progresivamente sometida al parlamento que conllevó la llegada del liberalismo. Y así ha sabido mantenerse incluso en democracia, a pesar de ser una institución que, en la mayoría de las ocasiones, ni siquiera ha sido elegida por sufragio.

Muchas de las actuales monarquías parlamentarias sitúan a la Corona como una institución representativa a nivel simbólico y apenas dispuesta de poder real. Y si es cierto que algunas de ellas, como la británica, la noruega, la española o la luxemburguesa conservan competencias ejecutivas, la realidad es que o bien no las ejercen o bien lo hacen a modo de mero refrendo de aquello estipulado con anterioridad por los respectivos Gobiernos. En contraposición a lo que sucedía en épocas pasadas, los monarcas actuales no toman parte de las decisiones políticas, y según reflexiona Javier Moreno Luzón, esta pérdida de poder efectivo ha contribuido a que las Casas Reales hayan sobrevivido hasta nuestros días ${ }^{2}$. Es pues en el ámbito representativo y ceremonial donde la Corona encuentra, amén de su lugar dentro de las democracias parlamentarias, la vía para seguir afianzando y manteniendo sus vínculos con la ciudadanía y con las instituciones políticas. Para ello resulta fundamental la participación en este tipo de actos públicos de gente, que permiten a la Monarquía seguir presentándose a sí misma como una institución más del sistema democrático y cercana al pueblo.

En la España actual, como sucede en el Reino Unido, en Suecia o en otras latitudes, a la inauguración de la legislatura parlamentaria se le sigue atribuyendo la cualidad de entroncar directamente a la Corona con la voluntad de los ciudadanos, lo que contribuye a identificar a la Monarquía con las cámaras parlamentarias, a diferencia de lo que sucede con los jefes de Estado de ciertos países republicanos. Esta vertiente escénica está, en efecto, mucho menos cultivada en repúblicas parlamentarias como por ejemplo Francia o Italia, países, ambos, en los que la sesión inaugural de la legislatura no cuenta con la participación del jefe del Estado, que es el presidente del Estado, y que por lo tanto desagrega a la institución del poder de las cámaras parlamentarias. Por lo que respecta a Italia, el reglamento de la cámara de diputados, en su artículo 2.1, establece que la apertura de cada

2 J. Moreno Luzón, “La monarquía malherida”, Ayer, 100, (2015), pp. 251-264. 
nueva legislatura estará presidida, de entre los miembros electos, por el vicepresidente de mayor edad de la legislatura anterior o, en su defecto, por el representante electo de mayor edad, y que será este quien ofrezca un breve discurso inaugural ${ }^{3}$. De una forma similar discurre la apertura de la Asamblea Nacional francesa, cuyo reglamento, en su artículo primero, también contempla que sea el diputado de mayor edad el que conduzca la primera sesión y que sus funciones, como en el caso italiano, se limiten a tramitar la elección del presidente de la cámara baja y a la posibilidad de pronunciar unas breves palabras previas al inicio del curso político ${ }^{4}$.

El presente artículo tiene como pretensión analizar todos estos pormenores durante el período democrático español para reflexionar sobre el lugar que ha ocupado y que ocupa en el desarrollo de los mismos la Monarquía. Más concretamente, y como ya se ha dicho con anterioridad, el objetivo es demostrar que el actual ceremonial de apertura de la legislatura parlamentaria se asienta fundamentalmente en la liturgia operada durante el franquismo y no tanto en prerrogativas actuales ni en antecedentes liberales. Y que, por supuesto, tampoco supone una novedad acaecida en democracia. A su vez, el texto también aspira a poner de relieve cómo los medios de comunicación han moldeado la intervención de los actores implicados. Para todo ello, en primer lugar, se reflexionará sobre las aproximaciones historiográficas a este tipo de ceremoniales. A continuación, se analizará la configuración del rito: primero, el desfile previo y, en segundo lugar, el discurso del rey.

\section{ESTADO DE LA CUESTIÓN Y METODOLOGÍA}

En España, tanto Isabel II como Alfonso XII coincidieron en cuidar su dimensión pública con la voluntad de proyectar así una imagen de cercanía ${ }^{5}$, pero tal vez fuese Alfonso XIII, particularmente en los inicios de su reinado, quien sometió a la institución a un mayor grado de contacto social mediante la promoción de encuentros, de celebraciones y de festejos. No en vano, apenas transcurridos cuatro años desde que hubiese cumplido la mayoría de edad (1902-1906), el rey ya había estado de visita en todas y cada una de las provincias españolas ${ }^{6}$. Como demuestra el libro editado por Margarita Barral, semejante periplo a lo largo y ancho de la geografía española le permitió no solo ganar visibilidad sino también reforzar su dimensión pública y contribuir así a la nacionalización de los españoles. La autora, no obstante, señala como una de sus conclusiones más destacadas que la implicación de la sociedad civil en la organización de dichas visitas fue desigual. Si bien las élites políticas participaron en ellas de manera activa, por ejemplo, asumiendo los costes de banquetes o como destacados acompañantes de ceremonias, la mayoría de los ciudadanos lo hacían como meros espectadores más o menos receptivos a la presencia del monarca. Ello impidió, en última instancia, que esos acontecimientos se convirtieran en ritos litúrgicos populares, restando así efectividad al proceso de modernización de la Monarquía?.

Ya fuera por la necesidad de reforzar los vínculos entre el jefe del Estado y la población después del franquismo, para acercar la institución a la ciudadanía a la vez que se alejaba de la dictadura o por cualquier otro motivo, lo cierto es que tanto Juan Carlos I como,

3 Regolamento della camera dei deputati, 18 de febrero de 1971.

4 Règlement de l'Assemblée nationale, actualización de septiembre de 2019.

5 R. Sánchez (ed.), "Hacia una monarquía nacional: la Corona como agente de nacionalización en España (1833-1885)", Hispania: Revista Española de Historia, 79-262, (2019), pp. 323-500.

6 J. Moreno Luzón, “'¿El rey de todos los españoles?' Monarquía y nación”, en Ser españoles. Imaginarios nacionalistas en el siglo XX, Barcelona, RBA, 2013, p. 139.

7 M. Barral Martínez, "Introducción: Las visitas reales como medio de nacionalización: Alfonso XIII en España", en Alfonso XIII visita España: Monarquía y nación, Granada, Comares, 2016, pp. 1-24. 
más recientemente, Felipe VI han cuidado esta dimensión escénica mediante continuadas visitas y giras por España y por el extranjero, procurando siempre transmitir una imagen de Monarquía moderna y funcional $^{8}$. Así han propiciado oportunidades de presentarse públicamente, entre las que se cuentan las que son objeto de este estudio: las sesiones inaugurales de la legislatura, ocasiones para que la notoriedad pública de los reyes quede asociada a las instituciones parlamentarias y que ya en el siglo XIX fueron ampliamente utilizadas por los monarcas españoles de la época para vincularse al nuevo sistema político liberal que se empezaba a consolidar ${ }^{9}$. La Monarquía tuvo entonces que someterse a un proceso de renovación y los ceremoniales de apertura de Cortes revelan, al menos a nivel simbólico, esta evolución. Como indica Shirin M. Rai, los rituales delimitan mediante sus inclusiones y exclusiones la tradición y la modernidad, reproduciendo el poder de las instituciones implicadas ${ }^{10}$. Es decir, que el estudio de sus escenificaciones y de sus cambios a lo largo del tiempo permite acercarse a nuevas formas de entender el poder político, su naturaleza y su configuración.

Si bien en el caso particular de la historiografía española, y gracias a las aportaciones metodológicas de la historia cultural y de la historia del arte, se han producido en los últimos tiempos avances significativos respecto al estudio de la Monarquía ${ }^{11}$ y de otros actos de cariz más popular o cívico ${ }^{12}$, el análisis de las festividades y de los ceremoniales —no ya en un sentido amplio, en el que no reviste novedad alguna, dado que cuenta con una relevante tradición ${ }^{13}$, sino en lo concerniente a su relación con las instituciones parlamentarias- no ha resultado demasiado socorrido, por más que recientemente se hayan elaborado algunos estudios reveladores y que tienden a destacar la capacidad de estos actos festivos para reproducir y transformar el poder institucional ${ }^{14}$. En general, el estudio de las celebraciones de la Monarquía contemporánea y de sus vinculaciones con ceremoniales parlamentarios ha tomado como punto de referencia la reflexión que hace David Cannadine acerca de la Corona británica, aunque obviamente existan también otros precedentes inspiradores ${ }^{15}$.

8 J. Moreno Luzón, "La monarquía malherida...".

9 O. Luján "The descent of the King to the people's assembly: Monarchy and Liberalism in 19th Century State Opening of Parliament's ceremony", en Monarchy, Liberalism and the for Spain's Modernisation (1780-1931), New York, Routledge, (en prensa).

10 S. M. Rai, "Analysing Ceremony and Ritual in Parliament", The Journal of Legislative Studies, 16-3, (2010), pp. 284-297.

11 Algunas de las más recientes contribuciones en D. San Narciso Martín, "Celebrar el futuro, venerar la Monarquía. El nacimiento del heredero y el punto de fuga ceremonial de la monarquía isabelina (18571858)", Hispania, 77-255, (2017), pp. 185-215; J. Luengo Sánchez, "Representar la monarquía: festividades en torno a la reina niña (1833-1846)", en Culturas políticas monárquicas en la España liberal: Discursos, representaciones y prácticas (1808-1902), Valencia, Publicaciones de la Universidad de Valencia, 2013, pp. 109-129.

12 Entre ellas, J. Roca Vernet, "Fiestas cívicas en la revolución liberal: Entusiasmo y popularidad del régimen", Historia Social, 86, (2016), pp. 71-90; J. Roca Vernet, "Las fiestas cívicas del Trienio Progresista (18401843): progresistas enfrentados y desafío a la Regencia", Historia contemporánea, 56 (2018), pp. 7-45; D. Bussy Genevois, J.L. Guereña y M. Ralle (ed.), "Fêtes, sociabilités, politique dans l'Espagne contemporaine", Bulletin d'Histoire contemporaine de l'Espagne, 30-31, (1999-2000), pp. 11-316.

13 La historiografía francesa, en particular, ha destacado por el interés hacia el significado histórico de las fiestas. Entre otras muchas aportaciones, M. Vovelle, Les métamorphoses de la fête en Provence, Paris, Aubier-Flammarion, 1976; M. Ozouf, La fête révolutionnaire, Paris, Gallimard, 1976; O. Ihl, La fête républicaine, Paris, Gallimard, 1996.

14 S. M. Rai y R. E. Johnson (ed.), Democracy in practice: Ceremony and ritual in Parliament, New York, Palgrave, 2014.

15 A modo de ejemplo, A. J. Mayer, The Persistence of the Old Regime: Europe to the Great War, Nueva 
Más allá del exitoso término de la invención de la tradición, su ya clásica aportación incide en la creación y evolución del ritual a partir de la adaptación de viejas tradiciones y nuevas invenciones ${ }^{16}$. Además de evidenciar la contribución de la perspectiva cultural al análisis de la historia política, su conclusión más trascendente consiste en haber señalado que fue la adaptación de antiguas prácticas en un nuevo contexto y con una publicidad distinta lo que permitió consolidarlas en costumbres modernas.

Sin duda, el pueblo tuvo un papel significativo en la aceptación de la Monarquía como institución liberal y aún hoy mantiene un destacado rol en la aprobación de la misma. Deliberar exclusivamente sobre ello no es el objetivo de este trabajo, aunque sí se tendrá en cuenta la dimensión popular al reflexionar sobre estos procesos. Así lo sugieren las últimas aportaciones científicas acerca del lugar que ocupa la Corona en las democracias actuales, y que inciden en cómo se ha transformado para pasar a ser un componente más de la sociedad de consumo, filtrado por la influencia y por el poder de los medios de comunicación. En otras palabras, el entendimiento actual de la Monarquía está circunscrito al impacto del fenómeno mediático ${ }^{17}$, hasta el punto de producirse un consumo monárquico como producto cultural. $Y$ es precisamente esa faceta mediática lo que da sentido a su supervivencia en los tiempos actuales ${ }^{18}$.

Con el objetivo de examinar el papel de la Monarquía española en el ceremonial que inaugura la legislatura parlamentaria, este texto analizará el ritual a lo largo de las últimas décadas. En primer lugar, se prestará atención a los momentos previos y a lo que acontece en los aledaños del Congreso de los Diputados, particularmente el desfile. A continuación, se atenderá al desarrollo del acto en el interior del hemiciclo, a la recepción del rey y a su discurso. En todos estos momentos se apreciará cómo ha evolucionado la liturgia en relación a su aparición y a su consolidación a principios del siglo XIX y hasta el franquismo, mediante una comparativa que permitirá calibrar mejor su transformación a lo largo de la historia contemporánea española.

Para lograr los objetivos, se analizarán los discursos aparecidos en los Diarios de Sesiones del Congreso de los Diputados, así como las crónicas escritas de los periódicos y en la prensa de la época. Dada la consideración de la dimensión simbólica y escénica, el texto también examinará las retransmisiones televisadas de estos eventos (los más recientes disponibles en www.youtube.com) y las fuentes iconográficas que muestran la evolución ritual y de indumentaria.

\section{EL DESFILE Y LOS PROLEGÓMENOS: UN FORMATO CON HERENCIAS DEL PASADO}

El origen del ceremonial de apertura de la legislatura, resultado de la negociación entre la Corona, las instituciones parlamentarias y el pueblo —o sea, de intereses no siempre coincidentes_- se remonta a las Cortes de Cádiz de 1810, aunque fue a lo largo de la década de 1830 y, especialmente, de 1840, cuando se consolidó como un modelo que sufriría muy pocos cambios hasta 1923, y mediante el cual la Monarquía española consiguió integrar elementos simbólicos de las celebraciones monárquicas modernas a la

York, Pantheon Books, 1981.

16 David Cannadine, "The Context, Performance and Meaning of Ritual: The Bristish Monarchy and the 'Invention of Tradition', c. 1820-1977', en The Invention of Tradition, Cambridge, Cambridge University Press, 1983, pp. 101-164.

17 N. Blain y H. O'Donnell, Media, Monarchy and Power, Bristol, Intellect Books, 2003.

18 C. C. Otnes y P. Maclaran, Royal Fever: The British Monarchy in consumer culture, Oakland, University of California Press, 2015. 
nueva realidad liberal. A semejanza de las tradicionales comitivas reales, se instauró, por ejemplo, un desfile público compuesto únicamente por miembros de la familia real y de la Corte y que servía de antesala a la ceremonia. Si las instituciones parlamentarias mantenían su espacio de poder y así lo simbolizaban, sin ir más lejos, con la entrega al monarca del discurso de apertura que este debía pronunciar, la Corona también supo conservar una efectiva y significativa autoridad en el naciente régimen. Lo hacía mediante iniciativas como la del desfile, con las que conseguía no solo presentarse a sí misma y a algunos de sus renovados ceremoniales como elementos propios del liberalismo ${ }^{19}$ sino también como una institución inextricable del parlamentarismo y de sus rituales.

Las aperturas de Cortes, además, así como otros ceremoniales similares, sirvieron a la Corona en su constante búsqueda de la aclamación popular, y si bien lo hacía desde una posición pasiva, la concurrencia del pueblo resultaba siempre necesaria para legitimar el lugar que la realeza ocupaba en el régimen parlamentario liberal. Vinculación popular en busca de legitimidad que sería, por cierto, la que propiciase que ya en democracia se recuperara el acto adecuándolo a la nueva realidad política.

En la actualidad, la Corona ya no es sujeto titular de poder político como lo era en el régimen de la soberanía compartida de las Constituciones de 1845 y 1876 . Es cierto que sigue conservando competencias políticas, pero su ejecución es mero simbolismo. El monarca puede convocar y disolver las Cortes según el artículo 62.b de la Constitución de 1978. Sin embargo, ya no lo hace a su merced como en el siglo XIX, sino que profesa esa capacidad de acuerdo con las directrices del Gobierno, que es quien ostenta en realidad - mediante el jefe del Ejecutivo - la capacidad de convocar elecciones. Lo mismo ocurre con la mayoría de Monarquías parlamentarias europeas. Por ejemplo, en el Reino Unido todo proyecto de ley tiene que ser aprobado por la reina, además de por ambas cámaras parlamentarias, para convertirse en ley. Como nos recuerdan Robert Rogers y Rhordri Walters, esta prerrogativa se mantiene únicamente a nivel simbólico, dado que la reina no tiene posibilidad política alguna de rechazar un proyecto de ley ${ }^{20}$. Y cuando algún monarca ha osado hacerlo, como lo hiciese el Gran Duque Henry de Luxemburgo al negarse a firmar y sancionar una ley sobre la eutanasia, el parlamento del país votó al unísono para modificar la Constitución y limitar así su capacidad ejecutiva, de manera que desde 2008 las leyes ya no requieren de su beneplácito para salir adelante ${ }^{21}$.

El monarca, pues, ya no representa una institución central del poder político, sino más bien una institución simbólica. Trasladado al ritual de inauguración de la legislatura parlamentaria, si a lo largo del siglo XIX uno de los actos más destacados acostumbraba a ser el desfile real previo, en la actualidad, y a falta de cortesanos ${ }^{22}$, lo que protagoniza el rey antes de entrar al Congreso de los Diputados se parece más a un paseo que discurre íntegramente por las inmediaciones del hemiciclo. El cambio es significativo. En Ios ceremoniales de apertura de 2016 y 2020, por ejemplo, Felipe VI, la reina y sus dos hijas llegaron en coche hasta el inicio de la Carrera de San Jerónimo —precedidos, eso sí, de la Guardia Real montada a caballo—, donde fueron recibidos por el presidente del Gobierno antes de trasladarse a pie hasta la entrada y ser atendidos por las autoridades parlamentarias después de que el rey pasara revista a un batallón de honores formado por miembros del Ejército y de la Guardia Civil.

19 O. Luján, "Escenificaciones de poder en el ceremonial de las aperturas de Cortes españolas del siglo XIX", Hispania: Revista Española de Historia, 79-261, (2019), pp. 99-126.

20 R. Rogers y R. Walters, How Parliament Works, London, Pearson, 1987, p. 40.

21 https://www.theguardian.com/world/2008/dec/12/luxembourg-monarchy (Consultado: 11-03-2020).

22 T. Burns Marañón, La Monarquía necesaria: Pasado, presente y futuro de la Corona en España, Barcelona, Planeta, 2007, pp. 17-18. 
Si se compara con los fastuosos ceremoniales del siglo XIX, podría parecer que el monarca hubiese optado por reducir su protagonismo de acuerdo a un simbólico sometimiento al poder encarnado por las instituciones parlamentarias, depositarias de la soberanía nacional. Actitud que le acercaría al ceremonial sueco, que desde la década de 1970 ha hecho una apuesta por la sobriedad al disminuir la exhibición de joyas y ostentosos atuendos, aunque no hayan desaparecido del todo ${ }^{23}$ y a pesar de que se mantiene un paseo en carruaje para asistir al acto protocolario ${ }^{24}$. Y le alejaría, en cambio, del modelo de apertura de otras Monarquías parlamentarias, como la británica, que sigue manteniendo el desfile y una pomposidad monárquica más que considerable: sirva de ejemplo el traslado de la corona imperial británica al palacio de Westminster y el desplazamiento de la reina Isabel II en una carroza majestuosa decorada en oro ${ }^{25}$.

Significativamente alejados, por tanto, de sus orígenes decimonónicos, todos estos preliminares no han variado sustancialmente desde $1979^{26}$, pero la novedad de sus usos no hay que situarla tampoco en el periodo propiamente democrático, sino más bien en el ceremonial de apertura de las Cortes franquistas, que a su vez tuvo continuidad en la sesión inaugural del 22 de julio de 1977. Aunque retomado a la par que la democracia, una vez aprobada la Constitución y celebradas unas elecciones completamente libres, lo cierto es que el acto inaugural de las legislaturas hasta la fecha sigue manteniendo un vínculo ineludible con el rito en época franquista. Para empezar, convertir el pomposo desfile de antaño en algo más parecido a un sencillo paseo no es acaso un cambio que resulte más deudor de la voluntad de celebrar un acto más austero que el que solía darse en tiempos de Isabel II o de Alfonso XIII que del influjo de la herencia del ritual franquista. Recordemos que por lo que respecta al dictador, este llegaba también a las inmediaciones del Congreso de los Diputados en coche cerrado, como ahora lo hace el rey, abandonando igualmente el vehículo entre la calle de Cedaceros y la Carrera de San Jerónimo ${ }^{27}$. Las similitudes llegan a tal punto que incluso el automóvil usado por ambos jefes del Estado sigue siendo el mismo, un Rolls-Royce Phantom IV adquirido por el dictador en 1952 y cuyo valor asciende a los 650.000 euros, uno de los vehículos oficiales más caros del mundo ${ }^{28}$ y cuyo uso está lejos de evocar precisamente austeridad.

En segundo lugar, los miembros del Gobierno y de la mesa de las Cortes recibían al dictador a las puertas del Congreso, a semejanza de lo acostumbrado recientemente. También la actual escenificación militar del ceremonial encuentra sus raíces en la apertura de las Cortes franquistas. Si a lo largo del siglo XIX y principios del XX las inauguraciones del curso político contaron, como ahora, con la presencia de tropas de la Guardia Real, e incluso con otros regimientos a principios del siglo pasado, su participación se circunscribía fundamentalmente en la comitiva durante el desfile ${ }^{29}$. En cambio, es con la llegada del

23 http://www.thecourtjeweller.com/2018/09/swedish-opening-of-parliament-jewels.html (Consulta: 10-032020).

24 H. LeeMiller, "Swedish Royal Family attends Opening of Parliament", https://royalcentral.co.uk/europe/ sweden/swedish-royal-family-attends-opening-of-parliament-130293/ (Consulta: 10-3-2020).

25 "Queen's new state coach celebrates British history", https://www.itv.com/news/2014-06-03/queens-newstate-coach-celebrates-years-of-british-history/ (Consulta: 10-03-2020).

26 "Los Reyes, en las Cortes", La Vanguardia, 10 de mayo de 1979, p. 10.

27 "Franco abrió ayer las Cortes", La Vanguardia, 18 de noviembre de 1967, p. 1.

28 G. Mateo, "El Rolls-Royce de Felipe VI, entre los coches oficiales más caros", El Español, 5 de mayo de 2018 , https://cronicaglobal.elespanol.com/graficnews/rolls-royce-felipe-vi-coches-oficiales-caros_158957_102.html (Consulta: 10-03-2020).

29 La Correspondencia de España, 15 de junio de 1910, p. 1. 
franquismo con la que toma mayor relevancia la participación de las Fuerzas Armadas, entendidas ya no como un mero adorno, sino como actores destacados. Vestido con uniforme de capitán general, como generalísimo de las Fuerzas Armadas, Franco solía pasar revista a compañías del Ejército antes de entrar a las Cortes y mientras una banda interpretaba el himno nacional. Usos y costumbres, uniforme de capitán general inclusive, que se heredaron, intactas, en los primeros años del actual formato ${ }^{30}$. El rey Juan Carlos I participó por primera vez en la que fue la apertura de la décima legislatura de las Cortes franquistas en noviembre de 1971, y lo hizo vestido con uniforme de general de brigada del Ejército de tierra — huelga decir que el uniforme de capitán general estaba reservado al dictador, como generalísimo de las Fuerzas Armadas ${ }^{31}$ _. Y en la apertura de las Cortes Constituyentes de 1977, Juan Carlos I, ya como jefe del Estado, decidió presentarse igualmente ataviado con el uniforme de capitán general, tal y como lo había hecho hasta entonces Franco ${ }^{32}$.

Sin embargo, y acaso debido al foco mediático al que está sometido y que analiza hasta el más mínimo detalle, el monarca ha ido adaptando su indumentaria a la realidad del siglo XXI. Así lo demuestra el hecho de que Juan Carlos I vistiese uniforme de gala de capitán general hasta la tercera legislatura de la democracia (en 1986) ${ }^{33}$, pero que a partir de entonces cambiase su atuendo por un traje, a semejanza del que suelen vestir la mayoría de los políticos. De hecho, y dejando de lado la ceremonia de su coronación, en los últimos años el propio Felipe VI ha restringido el uso del uniforme militar a actos castrenses o de simbología marcadamente militar, como es el día de la Hispanidad. También lo hacen otras casas reales: Harald I de Noruega ante la guardia del rey o los príncipes William y Harry del Reino Unido representando a los regimientos militares de los que forman parte. Símbolo de estatus social, el uniforme ofrece una imagen de autoridad y poder, y en el caso de los militares refleja el rango y, por extensión, exhibe posición social ${ }^{34}$. El mismo rey consorte de Isabel II —Francisco de Asís - ya había vestido así a mediados del siglo XIX haciendo uso de sus ropajes como elemento de distinción.

En la actualidad, la utilización del uniforme militar por parte del monarca español está íntimamente ligada a la competencia como "el mando supremo de las Fuerzas Armadas" que le atribuye el artículo 62.h de la Constitución española de 1978. Y en cuanto a ese cambio de vestimenta recién mencionado, que el uniforme militar haya dado paso al traje de gala podría pensarse que no atiende únicamente a una voluntad de desvincularse de la visión impositiva que en general se tiene de las armas, o al hecho de pretender aparecer ante la opinión pública como un civil más, sino, y por encima de todo, a la necesidad de distanciarse en la medida de lo posible de la escenificación franquista, a pesar de mantener vigente el pase de revista a las tropas.

\section{DE INDISCUTIBLE A DISCUTIDO: EL MONARCA EN LAS APERTURAS DE CORTES}

Amén del cambio de atuendo ya mencionado con anterioridad, otra de las diferencias sustanciales tiene que ver con la exposición mediática del acto. No resulta descabellado

30 "Franco abrió ayer las Cortes", La Vanguardia, 18 de noviembre de 1967, p. 1.

31 La Vanguardia, 19 de noviembre de 1971.

32 http://www.congreso.es/portal/page/portal/Congreso/Congreso/CG_Corona/LegCons_apertura (Consulta: 10-03-2020).

33 Consulten las imágenes en http://www.congreso.es/portal/page/portal/Congreso/Congreso/CG_Corona/ IIILeg_apertura (Consulta: 10-03-2020).

34 N. Joseph y N. Alex, "The Uniform: A Sociological Perspective", American Journal of Sociology, 77/4, (1972), pp. 719-730. 
pensar que hoy en día ya no importa tanto el público que se congrega en los alrededores del Congreso como la transmisión en directo de la apertura que realiza la televisión. De hecho, se sigue confiriendo a la ciudadanía un papel de mero espectador, papel que a lo largo de toda la historia contemporánea solo fue distinto en los inicios y finales del Sexenio Democrático (1868-74), cuando se intentó dar cierto protagonismo al pueblo mediante la promoción de desfiles de voluntarios.

La Casa Real tiene muy en cuenta esa exposición mediática a la hora de coordinar una puesta en escena que, ante el constante análisis que se realiza de cualquiera de las actividades públicas de la institución, parece calculada al milímetro para dicha retransmisión. El coche de los reyes suele llegar poco después de que conecte la televisión, y una vez salen sus majestades del vehículo se mantienen en todo momento pendientes de las cámaras, subordinando sus movimientos al seguimiento periodístico que se hace de ellos. Dicho ánimo casi coreográfico pone de acuerdo tanto a los partidarios como a los detractores de la Monarquía, y tampoco es casual que los miembros de los partidos políticos considerados republicanos no se levanten o no aplaudan la entrada de los reyes en el hemiciclo. Y si bien es cierto que la mayoría de los representantes políticos siguen poniéndose en pie para recibir al rey, más allá de dicho reconocimiento a la institución, hoy día ya no es el monarca quien les indica a los parlamentarios cuándo deben volver a sentarse. De hecho, en los últimos años algunos representantes políticos, en particular de Podemos y de partidos nacionalistas e independentistas, o se han ausentado de toda la sesión —como ERC y Bildu en 2016, y los mismos, junto a JxCat, BNG y CUP en 2020-, o del desfile previo —PNV en 2016_, o del desfile y de la salutación —Unidos Podemos y Compromís en 2016 - , o se han mantenido sentados sin aplaudir la entrada del monarca como muestra de rechazo — tal como hizo la bancada del PNV en $2020^{35}$. Consideraciones al hilo de las cuales cabría destacar también cómo la reciente entrada de Podemos en el primer Gobierno de coalición de la democracia, junto al PSOE, ha dado lugar a la extraña situación acaecida durante la inauguración de 2020, en la que los ministros del partido liderado por Pablo Iglesias aplaudieron al rey mientras que el resto de parlamentarios de la misma formación se abstenían de hacerlo.

Parece apropiado recordar que la desaprobación de la Monarquía por parte de los partidos independentistas y nacionalistas no es nueva, pues ya en 1979 la minoría catalana -integrada por representantes de CIU y ERC - y PNV no aplaudieron a Juan Carlos I en su entrada al hemiciclo ${ }^{36}$. No quiere decir esto, sin embargo, que las relaciones entre los conservadores catalanes y el monarca hayan sido siempre de abierta hostilidad. Sin ir más lejos, después del golpe de estado del 23-F de 1981, la Generalitat de Cataluña encabezada por Jordi Pujol rindió homenaje al Ejército y a la Corona, calificándolo de alto honor, en motivo de la celebración de la semana de las Fuerzas Armadas en Barcelona ${ }^{37}$. A decir verdad, la presencia del monarca en las inauguraciones de las legislaturas parlamentarias no se había cuestionado nunca. E incluso en 2014, en pleno Procés, el entonces presidente de la Generalitat, Artur Mas, asistió a la proclamación de Felipe VI como rey, si bien forzado por su compañero de partido Duran i Lleida ${ }^{38}$.

35 En la apertura de Cortes de noviembre de 2016 mostraron su aprobación al Rey, con aplausos, diputados y senadores del Grupo Parlamentario Popular, del Grupo Parlamentario Socialista, del Grupo Parlamentario Ciudadanos y algunos del Grupo Parlamentario Mixto. Vean Diario de Sesiones de las Cortes Generales: XII legislatura, núm. 1, 17 de noviembre de 2016, p. 1-7.

36 "Los Reyes, en las Cortes", La Vanguardia, 10 de mayo de 1979, p. 8.

37 J. F. Fuentes, Con el rey y contra el rey: Los socialistas y la Monarquía. De la Restauración canovista a la abdicación de Juan Carlos I (1879-2014), Madrid, La Esfera de los libros, 2016, p. 302.

38 A. Fernández, "Duran Lleida doblega a Artur Mas para que asista a la proclamación del Rey Felipe VI", 
Pero en los últimos tiempos la realidad es que cuestionar a la monarquía se ha convertido en un valor al alza que no solo manejan los independentistas, y que pone en evidencia el relevo de Juan Carlos I por Felipe VI en 2014. La implicación de la Casa Real en escándalos de corrupción como el caso Nóos, la participación del rey emérito en cacerías de elefantes junto a su amante Corinna Larsen y los presuntos escándalos de corrupción que los atañen a ambos por una supuesta donación de 100 millones de dólares del rey de Arabia Saudí39, el auge de fuerzas republicanas o de voces que empiezan a cuestionar la Monarquía son algunos de los elementos que han contribuido de una manera u otra al deterioro de su imagen pública e incluso a su cuestionamiento como institución vinculada al sistema político español, hasta el punto de haber dejado el Centro de Investigaciones Sociológicas de preguntar a la ciudadanía española acerca de la Corona ${ }^{40}$.

En la actualidad, se pueden encontrar todo tipo de informaciones en los medios, que en contradicción entre ellas ensalzan tanto la popularidad de Felipe VI y de la Monarquía española ${ }^{41}$ como cuestionan su apoyo y destacan el auge de los partidarios de celebrar un referéndum sobre el modelo de estado ${ }^{42}$. Muestras, todas ellas, de la necesidad del rey de regular su comportamiento público si quiere ganarse una imagen socialmente aceptable y alejarse de los escándalos que han acompañado a la institución los últimos años ${ }^{43}$.

\section{EL DISCURSO DEL REY}

Además del desfile y de la recepción, el otro elemento que tradicionalmente ha caracterizado el ceremonial ha sido el discurso del rey. A lo largo del siglo XIX y hasta 1923 era el acto más importante dentro de las Cortes, y como aún sucede en el sistema británico su función principal era presentar las líneas maestras de actuación del Gobierno en la legislatura que recién comenzaba. En el caso español y desde la década de 1830, el discurso de la Corona lo escribieron siempre los gabinetes. Ellos fueron quienes tuvieron que dar cuentas del contenido, debido a la inviolabilidad del monarca, no sujeto a responsabilidad, y se entendía el acto como el momento propicio para la presentación del programa político por parte del gobierno y de la valoración de la acción gubernamental por parte de la oposición. En otras palabras, una oportunidad para el debate parlamentario y un momento configurado como pieza básica del régimen de soberanía compartida.

Dicho lo cual, convendría hacer un par de aclaraciones. Por un lado, que, si bien leía un discurso elaborado por el Gobierno y, legalmente, no tenía que responder por él, en

El Confidencial, 8 de junio de 2014, https://www.elconfidencial.com/espana/cataluna/2014-06-08/duran-lleidadoblega-a-artur-mas-para-que-asista-a-la-proclamacion-del-rey-felipe-vi_143201/ (Consulta: 10-03-2020)

39 "Suiza investiga una supuesta donación de 100 millones de dólares del rey de Arabia Saudí a Juan Carlos I", Eldiario.es, 3 de marzo de 2020, https://www.eldiario.es/politica/Suiza-investiga-millonaria-CorinnaLarsen_0_1001950963.html (Consulta: 10-03-2020).

40 En el último año del reinado de Juan Carlos I (2013) la nota media atribuida a la institución no llegaba ni al aprobado.

41 A. Martínez-Fornés, "El rey logra su mejor valoración de la Monarquía desde su restauración", $A B C, 6$ de agosto de 2018, https://www.abc.es/espana/abci-logra-mejor-valoracion-monarquia-desderestauracion-201808052317_noticia.html (Consulta: 10-03-2020).

42 J. L. Marín, "El apoyo a la monarquía, por debajo del 50\%", Electomanía, 25 de julio de 2018, https:/l ctxt.es/es/20180725/Politica/20983/electomania-encuesta-ctxt-monarquia-referendum.htm (Consulta: 10-032020).

43 Al cierre de este texto trascendió la renuncia de Felipe VI a la herencia de su padre y la retirada de la asignación procedente de los presupuestos de la Casa Real a Juan Carlos I a causa de su posible vinculación con unos fondos opacos. M. Alcázar, "El Rey renuncia a la herencia de Juan Carlos I y le retira la asignación", La Vanguardia, 15 de marzo de 2020, https://www.lavanguardia.com/politica/20200315/474164914213/reyfelipe-iv-renuncia-herencia-juan-carlos-i-retira-asignacion-casa-real.html (Consulta: 17-03-2020). 
último término era el propio rey quien ponía un gabinete u otro, de modo que también la Corona, al menos a ojos de la ciudadanía, era corresponsable y susceptible de ser juzgada moralmente por sus acciones, como así lo demuestra la revolución de 1868. Y por el otro, que abrir las Cortes con un discurso de partido politizaba la Corona asociándola con la formación política que lideraba el poder en ese momento. Dos aspectos que, precisamente, no se quisieron reproducir en una democracia como la actual.

En 1979 tuvo lugar un debate acerca de si el rey tenía que intervenir en la inauguración de la legislatura o si, por el contrario, debía permanecer en silencio. Dado que el artículo 56 de la Constitución de 1978 establece la inviolabilidad del monarca, se llegó a plantear incluso si sus palabras, en caso de ser pronunciadas, tenían que ser refrendadas por el presidente del Gobierno de acuerdo con el artículo 64 de la Carta Magna. La UCD, entonces en el Ejecutivo, era partidaria de evitar una autorización explícita, pues entendía que no era necesaria si la intervención se limitaba a una salutación y no entraba en cuestiones de gabinete ${ }^{44}$. Se querían separar así las palabras del rey de cualquier tipo de observación política, a diferencia del papel que habían desempeñado sus antecesores, desde Fernando VII hasta Alfonso XIII, o incluso el mismo dictador, quien utilizaba la ocasión ceremonial como un instrumento cualquiera de propaganda política. Sirva de ejemplo el siguiente fragmento de la apertura de 1952:

Si discurrimos sobre la etapa de la vida del Mundo que hemos superado, y recordamos las conjuras y asechanzas que contra nuestra Nación se movieron, y contemplamos la obra legislativa realizada en estos mismos años, podemos apreciar mejor la eficacia de un sistema que, dando a la Nación seguridad y fortaleza, le ha permitido continuar su obra legislativa serenamente, sin aquellas claudicaciones a que en otros tiempos conducían a la Nación a las especulaciones de los partidos sobre las dificultades de la Patria ${ }^{45}$.

La propuesta de la UCD, por tanto, era que el monarca se mantuviera en un segundo plano, y que, de acuerdo con ella, Juan Carlos I interviniese después de las palabras del presidente del Ejecutivo, quien ofrecería el tradicional discurso vinculado al programa a desempeñar. Lo cierto es que en democracia nunca ha intervenido el jefe del Gobierno sino el presidente del Congreso. Aunque ambos acostumbran a ser del mismo partido político, el discurso programático lo ofrece el primero en el transcurso del acto de investidura, mientras que las palabras del segundo durante las aperturas se remiten a generalidades de menor carga y estrategia política, como el reconocimiento de la tarea del rey y de los parlamentarios. Siendo este el quehacer general, resulta más bien excepcional la intervención, por ejemplo, de Manuel Marín en 2004, al tomar en consideración algunos de los proyectos que se preveían aprobar en la legislatura que empezaba: la reforma del Senado, la adopción de la Constitución europea o la incorporación de la posibilidad que las mujeres también pudieran ser reinas ${ }^{46}$.

Acaso fuese esa falta, digamos, de calado político en las aperturas a partir de 1979 lo que propició más espacio al discurso del rey y ayudó a consolidar una suerte de tercera vía de facto, alejada de la opción barajada en su momento por la UCD y del papel que desempeñaban los reyes en el siglo XIX. Es cierto que el monarca nunca ha aprovechado para comentar propiamente el programa del Ejecutivo, pero sí para mencionar algún que otro reto del curso político. En 2011, sin ir más lejos, Juan Carlos I se refirió a la "obligación"

44 "Crónica Política", Mediterráneo, 10 de mayo de 1979, pp. 1-2.

45 Boletín Oficial de las Cortes Españolas: legislatura 1952-1955, núm. 394, 16 de mayo de 1952, p. 7282.

Diario de Sesiones de las Cortes Generales: VIII legislatura, núm. 1, 22 de abril de 2004, p. 2. 
de los representantes políticos de "contribuir con decisión y eficacia a la superación" de la crisis económica, y también a "reforzar la confianza en las instituciones" 47 , palabras que culminaban las intensas reuniones mantenidas por el rey con el mundo empresarial y que fueron criticadas desde el PCE por entenderlas como un aval contra los derechos de los trabajadores $^{48}$.

Lejos de lo que pudiera parecer desde una perspectiva más reciente, el posicionamiento del PCE respecto a la Monarquía durante la transición fue de simple aceptación. El precio a pagar por los comunistas para ser legalizados ante las elecciones de junio de 1977 fue abandonar el republicanismo ${ }^{49}$, y su actitud resultó bastante menos intransigente que la del PSOE, como lo demuestra el hecho de que sus más importantes dirigentes de entonces calificaran el discurso de apertura de Juan Carlos I en 1977 de "maravilloso 50", o que le aplaudieran sin reparos en sus actos públicos ${ }^{51}$.

Los socialistas, en cambio, mantuvieron su apuesta republicana e incluso trataron de simbolizar cierto distanciamiento con la Corona durante la inauguración de la legislatura de 1977, en la que recibieron al monarca en pie, pero en silencio, si bien terminaron aplaudiendo su discurso. Asimismo, se abstuvieron en la votación del artículo 1.3 de la Constitución de 1978, que define la forma política del Estado español como Monarquía Parlamentaria, aunque votaron a favor del título II dedicado exclusivamente a la Corona ${ }^{52}$. Como ha señalado Juan Francisco Fuentes, el PSOE empezó a acercarse a los monárquicos contrarios a la dictadura a finales de la Segunda Guerra Mundial, con una estrategia posibilista de unidad de acción frente al enemigo franquista. Eso se tradujo en una aceptación progresiva de la Monarquía como forma de Estado, siempre que el rey admitiese un régimen de libertades. Es decir, la prioridad era alcanzar la democracia, y si eso pasaba por la aceptación de la Monarquía, se daría por bueno con el necesario refrendo de los ciudadanos.

La vía que lo hacía posible era la defensa del plebiscito, que dejaba en manos de los españoles la decisión final acerca del modelo de Estado. Semejante maniobra les permitía llegar a acuerdos con monárquicos liberales, aunque luego desecharan esa opción tras la muerte de Franco ${ }^{53}$ o consideraran que la aprobación del referéndum de la Constitución en diciembre de 1978 equivalía al reivindicado referéndum, admitiendo así la Monarquía. Si en la apertura de la legislatura parlamentaria de 1979 solo fueron "una parte de los parlamentarios socialistas" los que recibieron en pie y sin aplaudir al rey —entre ellos el número dos, Alfonso Guerra ${ }^{54}$ _, en 1982 el gobierno socialista de Felipe González y sus parlamentarios exhibieron ya al completo entusiastas aplausos ${ }^{55}$.

Tras pasar de puntillas por el debate acerca de la forma de Estado y entendiendo que la Monarquía podía generar más consenso, tampoco se entró a debatir el rol de la institución en el ceremonial de inauguración de la legislatura, de forma que se permitió que se reprodujeran conductas heredadas del periodo franquista, en particular en la

47 Diario de Sesiones de las Cortes Generales: X legislatura, núm. 1, 27 de diciembre de 2011, p. 3-4.

48 "EI PCE denuncia que el Rey trate de imponer medidas contra los trabajadores", Europa Press, 14 de febrero de 2010, https://m.europapress.es/nacional/noticia-pce-denuncia-rey-trate-imponer-medidas-contratrabajadores-20100214171409.html (Consulta: 10-03-2020).

49 G. Morán, Adolfo Suárez. Ambición y destino, Barcelona, Debate, 2009.

50 J. F. Fuentes, Con el rey y contra el rey..., p. 279.

51 "Los Reyes, en las Cortes", La Vanguardia, 10 de mayo de 1979, p. 8.

52 J. F. Fuentes, Con el rey y contra el rey..., pp. 279-281.

53 L. C. Hernando, EI PSOE y la monarquía. De la posguerra a la transición, Madrid, Eneida, 2013.

54 "Los Reyes, en las Cortes", La Vanguardia, 10 de mayo de 1979, p. 8.

55 J. F. Fuentes, Con el rey y contra el rey..., p. 307. 
previa, y se concedió un espacio adecuado para amplificar la dimensión política del rey mediante su intervención en el hemiciclo. En ese contexto, las referencias a las relaciones internacionales, en particular con Europa e Iberoamérica, la situación económica o la lucha contra el terrorismo han sido algunos de los principales y constantes elementos que se han ido repitiendo año tras año en su discurso. Aunque las palabras del rey en sus intervenciones no han implicado nunca un sostenimiento o rechazo de la actuación del Gobierno entrante, sí que han mantenido un cariz político innegable, vinculado de hecho a sus obligaciones constitucionales, pues según el artículo 56.1 de la Constitución al rey le corresponde "la más alta representación del Estado español en las relaciones internacionales". Asimismo, el planteamiento de guardar y hacer guardar la Constitución es una idea que también se repite con asiduidad, ya en $1979^{56}$ o ya en 2004 , cuando el monarca indicó:

Esta es además una ocasión que deseo aprovechar para reafirmar, junto con la Reina y el Príncipe de Asturias, el firme compromiso de entrega a España y a todos los españoles que anima a la Corona, con lealtad a la Constitución y a los valores y principios que consagra ${ }^{57}$.

No debe resultar extraño que así sea, teniendo en cuenta que la Constitución de 1978, en su artículo 61.1, estipula que el rey "prestará juramento de desempeñar fielmente sus funciones, guardar y hacer guardar la Constitución y las leyes y respetar los derechos de los ciudadanos y de las Comunidades Autónomas".

Lo mismo ha sucedido en tanto que símbolo de la "unidad y permanencia" del Estado, que de acuerdo con el artículo 56.1 "arbitra y modera el funcionamiento regular de las instituciones". Por eso se refirió Juan Carlos I en repetidas ocasiones a la amenaza terrorista de ETA y apeló a "la unidad en la defensa de los valores democráticos que compartimos para que desaparezca de nuestra convivencia la violencia terrorista ${ }^{58 " . ~ M a ́ s ~ r e c i e n t e m e n t e, ~}$ ha sido el independentismo catalán el que ha alertado a Felipe VI del peligro que supone para la unidad del Estado. En 2016 insistió en "el respeto y observancia de la ley y de las decisiones de los tribunales" como "garantía esencial de la democracia" y reclamó diálogo dentro del respeto a la ley:

España no puede negarse a sí misma tal y como es; no puede renunciar a su propio ser y no puede, en fin, renunciar al patrimonio común construido por todos y desde el que debemos seguir edificando un futuro compartido ${ }^{59}$.

Después de casi un año de inactividad política y de dos elecciones generales, las palabras de Felipe VI fueron calificadas de "discurso político" por El País, en particular por la crisis de gobernabilidad del Estado, por sus apelaciones a la regeneración democrática y por la persecución de la corrupción y la potenciación de la vertiente internacional ${ }^{60}$. Aún así, como indica Jordi Canal, el papel del rey durante el año de inactividad fue de neutralidad, si se atiende al hecho de que no forzó la aplicación del artículo 99 de la Constitución que le permite proponer un candidato a la presidencia ${ }^{61}$. Sin embargo, ante la repetición de

56 Diario de Sesiones de las Cortes Generales: I legislatura, núm. 1., 9 de mayo de 1979, p. 177-179.

57 Diario de Sesiones de las Cortes Generales: VIII legislatura, núm. 1., 22 de abril de 2004, p. 3.

58 Diario de Sesiones de las Cortes Generales: VII legislatura, núm. 1, 3 de mayo de 2000, p. 4-5.

59 Diario de Sesiones de las Cortes Generales: XII legislatura, núm. 1, 17 de noviembre de 2016, p. 4-7.

60 "Un discurso político", El País, 18 de noviembre de 2016, https://elpais.com/elpais/2016/11/17/ opinion/1479408670_461154.html (Consulta: 10-03-2020).

61 J. Canal, La monarquía en el siglo XXI, Madrid, Turner, 2019, p. 79. 
bloqueo en agosto de 2019, sin Gobierno constituido ni presidente elegido por el parlamento después de transcurridos más de tres meses desde las elecciones generales, Felipe VI instó a los partidos, aunque sin efectividad alguna, a ponerse de acuerdo como mejor solución "antes de ir a otras elecciones"62.

Tal vez la vertiente más política del rey apareció en el discurso pronunciado el 3 de octubre de 2017, dos días después de la celebración del referéndum de independencia en Cataluña. Aunque no se trate de una intervención formulada en el contexto del ceremonial de inauguración de la legislatura parlamentaria resulta oportuno incorporarla aquí para ilustrar la capacidad de intervención de la Corona en el espacio político y de alejarse del modelo simbólico que había imaginado la UCD durante la transición. He aquí un fragmento de las contundentes palabras de Felipe VI el 3 de octubre de 2017:

Desde hace ya tiempo, determinadas autoridades de Cataluña, de una manera reiterada, consciente y deliberada, han venido incumpliendo la Constitución y su Estatuto de Autonomía, que es la Ley que reconoce, protege y ampara sus instituciones históricas y su autogobierno.

[...] En definitiva, todo ello ha supuesto la culminación de un inaceptable intento de apropiación de las instituciones históricas de Cataluña. Esas autoridades, de una manera clara y rotunda, se han situado totalmente al margen del derecho y de la democracia. Han pretendido quebrar la unidad de España y la soberanía nacional, que es el derecho de todos los españoles a decidir democráticamente su vida en común.

Por todo ello y ante esta situación de extrema gravedad, que requiere el firme compromiso de todos con los intereses generales, es responsabilidad de los legítimos poderes del Estado asegurar el orden constitucional y el normal funcionamiento de las instituciones, la vigencia del Estado de Derecho y el autogobierno de Cataluña, basado en la Constitución y en su Estatuto de Autonomía ${ }^{63}$.

La intervención volvía a poner de relieve un uso de los medios de comunicación muy planificado, con un formato de intervención excepcional y una apelación directa a la cámara. El rey no leyó ningún discurso en papel que le desconectara de la mirada de los telespectadores, sino que utilizó los recursos propios de cualquier presentador que lee el texto en el teleprompter para así dar la sensación de una comunicación directa y fluida. Dicho sea de paso, situación que no revestía novedad alguna si se tienen en cuenta los tradicionales mensajes de Navidad.

De todos modos, esas palabras sancionaban a nivel simbólico la aplicación por vez primera del artículo 155 de la Constitución ${ }^{64}$, que acarreaba la suspensión temporal de la autonomía catalana. El discurso del rey fue aprobado antes de su emisión y a regañadientes

62 A. M., "El Rey se pronuncia y pide a los partidos "una solución antes de ir a elecciones", El Confidencial, 4 de agosto de 2019, https://www.elconfidencial.com/espana/2019-08-04/rey-felipe-vi-bloqueo-politico-evitarelecciones_2161515/ (Consulta: 10-03-2020).

63 El mensaje íntegro en: https://elpais.com/politica/2017/10/03/actualidad/1507058161_929296.html (Consulta: 10-03-2020).

64 Cuyo contenido establece: "1. Si una Comunidad Autónoma no cumpliere las obligaciones que la Constitución u otras leyes le impongan, o actuare de forma que atente gravemente al interés general de España, el Gobierno, previo requerimiento al presidente de la Comunidad Autónoma y, en el caso de no ser atendido, con la aprobación por mayoría absoluta del Senado, podrá adoptar las medidas necesarias para obligar a aquélla al cumplimiento forzoso de dichas obligaciones o para la protección del mencionado interés general. 2. Para la ejecución de las medidas previstas en el apartado anterior, el Gobierno podrá dar instrucciones a todas las autoridades de las Comunidades Autónomas". 
por el entonces presidente del Gobierno, Mariano Rajoy ${ }^{65}$, poniendo en evidencia que la iniciativa procedía de la propia Casa Real y granjeándose tanto elogios como críticas por parte de las fuerzas políticas, estas últimas especialmente abundantes en Cataluña y procedentes tanto de políticos independentistas como de representantes de Podemos y del PSC, reprochándole no hacer mención de la palabra diálogo, como sí había hecho en el discurso inaugural de la legislatura de $2016^{66}$.

\section{CONCLUSIÓN}

El balance es, en conclusión, ambivalente. Por un lado, la Corona se ha ido adaptando a los tiempos actuales, en consonancia con un régimen democrático: ha eliminado los símbolos de cariz más impositivo, como el uniforme militar, procurando a su vez alejarse de la liturgia franquista y adaptándose a un ceremonial de formas y maneras menos pomposas. El acto, sin embargo, conserva todavía ciertas reminiscencias de la apertura de las Cortes franquistas, como por ejemplo la llegada de los reyes en el Rolls-Royce que utilizaba Franco o la presencia de la dimensión militar. Cabe recordar, además, que más que priorizar la sobriedad, la escenificación de un desfile más corto atiende a la mera herencia del formato usado durante la dictadura.

Por otro lado, el discurso del monarca ha tomado un cariz político en sus intervenciones parlamentarias, en particular en lo referente a las cuestiones relacionadas con la representación internacional o con la unidad del Estado, tal y como la Constitución de 1978 le encarga salvaguardar. Tal vez por ello, además de por la suerte de vacío político del que están provistas las palabras del presidente del parlamento, de un carácter más bien protocolario, se conceda espacio político al mensaje del rey, evocando así al arraigado papel que sus antecesores han tenido tradicionalmente en el sistema parlamentario español. En semejante estado de las cosas, la Corona no solo no ha eludido las amenazas que se ciernen sobre la unidad del Estado, sino que ha decidido intervenir con decisión, reforzando así su dimensión política y haciendo un uso instrumental de los medios de comunicación para transmitir sus mensajes.

El futuro esclarecerá hacia donde derivan todos estos pormenores, si son coyunturales o si se acaban convirtiendo en generalidad, y en qué medida favorecerán o desgastarán a la Monarquía parlamentaria española. Sin demasiado ánimo de especular, el diagnóstico parece evidente: si desde sus inicios el sistema parlamentario español concedió a la Corona amplias prerrogativas, situándola como base del mismo, y, a pesar de la pérdida de poder efectivo, el actual sistema constitucional sigue situándola como árbitro simbólico aunque central, es decir como una institución asociada al régimen constitucional de 1978, resulta difícil imaginar, pues, una oposición a la Monarquía que no pase, inexcusablemente, por la misma oposición al régimen. Lo que no resulta óbice para que el apoyo social al rey pueda verse, de una forma u otra, mermado en función de su comportamiento — como ya le sucediera a Juan Carlos I durante los últimos años de reinado- o que la exposición a la sociedad mediatizada pueda resultar tan favorable como perjudicial.

65 J. Canal, La monarquía..., p. 81.

66 "Las reacciones al mensaje del rey sobre Cataluña, de Iglesias a Casado", El Confidencial, 4 de octubre de 2017, https://www.elconfidencial.com/espana/cataluna/2017-10-04/independencia-cataluna-reaccionespartidos-politicos_1455043/ (Consulta: 10-03-2020); "Crítiques d'independentistes, comuns i PSC al discurs del rei", CCMA, 3 de octubre de 2017, https://www.ccma.cat/324/critiques-dindependentistes-comuns-i-psc-aldiscurs-del-rei/noticia/2812710/ (Consulta: 10-03-2020). 


\section{BIBLIOGRAFÍA}

Barral Martínez, M., "Introducción: Las visitas reales como medio de nacionalización: Alfonso XIII en España", en Alfonso XIII visita España: Monarquía y nación, Granada, Comares, 2016, pp. 1-24.

Blain, N. y O'Donnell, H., Media, Monarchy and Power, Bristol, Intellect Books, 2003.

Burns Marañón, T., La Monarquía necesaria: Pasado, presente y futuro de la Corona en España, Barcelona, Planeta, 2007.

Bussy Genevois, D., Guereña, J.L. y Ralle, M. (ed.), "Fêtes, sociabilités, politique dans l'Espagne contemporaine", Bulletin d'Histoire contemporaine de l'Espagne, 30-31, (1999-2000), pp. 11-316.

Canal, J., La monarquía en el siglo XXI, Madrid, Turner, 2019.

Cannadine, D., "The Context, Performance and Meaning of Ritual: The Bristish Monarchy and the 'Invention of Tradition', c. 1820-1977', en The Invention of Tradition, Cambridge, Cambridge University Press, 1983, pp. 101-164.

Fuentes, J. F., Con el rey y contra el rey. Los socialistas y la monarquía: de la Restauración canovista a la abdicación de Juan Carlos I (1879-2014), Madrid, La esfera de los libros, 2016.

Hernando, L. C., EI PSOE y la monarquía. De la posguerra a la transición, Madrid, Eneida, 2013.

Ihl, O., La fête républicaine, Paris, Gallimard, 1996.

Joseph, N. y Alex, N., "The Uniform: A Sociological Perspective", American Journal of Sociology, 77/4, (1972), pp. 719-730.

Kuhn, W. M., Democratic Royalism. The Transformation of the British Monarchy, 1861-1914, New York, Palgrave, 1996.

Luengo Sánchez, J., "Representar la monarquía: festividades en torno a la reina niña (1833-1846)", en Culturas políticas monárquicas en la España liberal: Discursos, representaciones y prácticas (1808-1902), Valencia, Publicaciones de la Universidad de Valencia, 2013, pp. 109-129.

Luján, O., "The descent of the King to the people's assembly: Monarchy and Liberalism in 19th Century State Opening of Parliament's ceremony", en Monarchy, Liberalism and the Struggle for Spain's Modernisation (1780-1931), New York, Routledge (En prensa).

Luján, O. "Escenificaciones de poder en el ceremonial de las aperturas de Cortes españolas del siglo XIX", Hispania: Revista Española de Historia, 79-261, (2019), pp. 99-126.

Mayer, A. J., The Persistence of the Old Regime: Europe to the Great War, New York, Pantheon Books, 1981.

Morán, G., Adolfo Suárez. Ambición y destino, Barcelona, Debate, 2009.

Moreno Luzón, J., "La monarquía malherida", Ayer, 100, (2015), pp. 251-264.

- “¿El rey de todos los españoles?' Monarquía y nación”, en españoles. Imaginarios nacionalistas en el siglo XX, Barcelona, RBA, 2015, pp. 133-167.

- $\quad$ "El rey de papel. Textos y debates sobre Alfonso XIII", en J. Moreno Luzón (ed.), Alfonso XIII: Un político en el trono, Madrid, Marcial Pons, 2003, pp. 23-58.

Otnes, C. C. y Maclaran, P., Royal Fever: The British Monarchy in consumer culture, Oakland, University of California Press, 2015.

Ozouf, M., La fête révolutionnaire, Paris, Gallimard, 1996.

Rai, S. M. y Johnson, R. E. (ed.), Democracy in practice: Ceremony and ritual in Parliament, New York, Palgrave, 2014.

Rai, S. M., "Analysing Ceremony and Ritual in Parliament", The Journal of Legislative Studies, 16-3, (2010), pp. 284-297.

Roca Vernet, J., "Las fiestas cívicas del Trienio Progresista (1840-1843): progresistas 
enfrentados y desafío a la Regencia", Historia contemporánea, 56, (2018), pp. 7-45.

- "Fiestas cívicas en la revolución liberal: Entusiasmo y popularidad del régimen", Historia Social, 86, (2016), pp. 71-90.

Rogers, R. y Walters, R., How Parliament Works, London, Pearson, 1987.

San Narciso Martín, D., "Celebrar el futuro, venerar la Monarquía. El nacimiento del heredero y el punto de fuga ceremonial de la monarquía isabelina (1857-1858)", Hispania: Revista Española de Historia, (2017), 77-255, pp. 185-215.

Sánchez, R. (ed.), "Hacia una monarquía nacional: la Corona como agente de nacionalización en España (1833-1885)", Hispania: Revista Española de Historia, 79-262, (2019), pp. 323-500.

Te Velde, H., "Cannadine, Twenty Years on. Moanrchy and Political Culture in NineteenthCentury Britain and the Netherlands", en Mystifying the Monarch: Studies on Discourse, Power, and History, Amsterdam, Amsterdam University Press, 2006, pp. 193-203.

Vovelle, M., Les métamorphoses de la fête en Provence, Paris, Aubier-Flammarion, 1976. 